\title{
Karakteristik Fungsional Agroforestry dan Kontribusi Terhadap Pendapatan Masyarakat Di Kecamatan Bulukumpa Kabupaten Bulukumba
}

\author{
A.Qamaru Zaman ${ }^{1 *}$, Samuel Paembonan ${ }^{1}$, Muhammad Restu \\ ${ }^{1}$ Fakultas Kehutanan, Universitas Hasanuddin, Makassar \\ *Email: zamanqamaru25@gmail.com
}

\begin{abstract}
This study aims to identify the functional characteristics of agroforestry, analyze the potential of agroforestry and calculate the contribution of agroforestry to community income. This research was conducted in Bulukumpa District, Bulukumba Regency. The data collected were primary data and secondary data where primary data were obtained directly from agroforestry management farmers and from field measurements on each community land to determine the vegetation structure and species composition. Secondary data were obtained from the village and subdistrict offices to determine the general condition of the research location. The data analysis used is the income and the contribution analysis used is the qualitative analysis of the agroforestry characteristics and the calculation of economic value using the income formula and the contribution formula to determine the contribution of agroforestry businesses to the total income of farmers. The results showed agroforestry efforts to increase community income with a contribution value to total income of $78.69 \%$ which was dominated by plantation crop income
\end{abstract}

Keywords: characterictics, agroforestry, contrbutioni, income DOI:10.24259/jhm.v12i2.5756

\section{PENDAHULUAN}

Agroforestri merupakan salah satu bentuk terpenting dari penerapan konsep perhutanan sosial. Nurrochmat (2005) mengatakan bahwa perhutanan sosial dapat dipahami sebagai ilmu dan seni menumbuhkan pepohonan dan tanaman lain di dalam dan di sekitar kawasan hutan dengan melibatkan masyarakat sekitar hutan untuk mencapai tujuan ganda meliputi pengelolaan hutan lestari dan peningkatan kesejahteraan masyarakat.

Agroforestry dalam penerapannya memiliki beragam karakteristik yang berbeda bila ditinjau dari segi fungsinya, terdapat fungsi yang berdasarkan aspek sosial-ekonomi, berdasarkan aspek sosial-budaya, serta berdasarkan aspek ekologi. Pada umumnya karakteristik yang tercermin dalam pengeloalaan lahan berbasis agroforestri oleh masyarakat lebih cenderung menunjukkan aspek pengelolaan yang menitikberatkan pada aspek sosial- ekonomi.

Pengelolaan agroforestry yang didasarkan pada aspek peningkatan sosial-ekonomi semata, dapat terlihat dengan komposisi jenis pada setiap pola agroforestry yang diterapkan oleh masyarakat pada lahannya, pada umumnya komposisi jenis yang terdapat pada lahan masyarakat dipengaruhi langsung oleh luas kepemilikan lahan oleh masyarakat yang menggarap lahannya. 
Luas kepemilikan lahan oleh masyarakat secara tidak langsung mempengaruhi masyarakat dalam memilih beragam komposisi tanaman yang akan diterapkan pada lahan garapannya, semakin rendah luas lahan yang dimilikinya, maka semakin rapat dan semakin banyak jenis tanaman yang ada dalam lahan tersebut, khususnya tanaman semusim. Hal ini menunjukkan bahwa luas lahan garapan dapat menunjukkan karakteristik fungsional berdasarkan aspek sosial ekonomi secara langsung.

Praktik agroforestri sudah cukup dikenal dan telah diterapkan secara luas oleh masyarakat di Kecamatan Bulukumpa sebagai bentuk perkebunan rakyat. Berkembangnya agroforestri di daerah ini tidak lepas dari sifat dan kemudahan pengelolaan yang lebih mudah dibandingkan dengan bentuk usahatani pertanian umumnya seperti padi sawah atau pertanian monokultur lainnya. Hal ini sejalan dengan pendapat Irwanto (2007) yang menyatakan bahwa dengan pola tanam agroforestri/tumpang sari dapat dikatakan bahwa masyarakat sudah dapat memanfaatkan lahan kosong (lahan yang tidak produktif) untuk menanam jenis-jenis tanaman lain (tananam palawija dan setahun).

Masyarakat saat ini seringkali melakukan pencampuran berbagai jenis tanaman dalam suatu lahan dengan alasan pemanfaatan lahan yang sempit dan juga beranggapan bahwa semakin bervariasi tanaman yang ada maka semakin besar pendapatan yang dapat dihasilkannya. Namun kenyataannya tidak semua kombinasi jenis tanaman pada agroforestry bisa bersinergi menghasilkan total produksi, seperti disinyalir Sanchez (1995) bahwa seringkali hasil dari agroforestry tidak meningkatmalah menurun.

Kombinasi campuran berbagai jenis tanaman pada pola tanam agroforestry yang saat ini dikembangkan masyarakat perlu dikaji strukturnya dan dievaluasi nilai ekonominya, agar tersedia informasi campuran berbagai jenis tanaman yang paling layak dikembangkan pada wilayah tersebut. Hal ini didukung hasil penelitian Widiarti \& Sukaesih (2008) yang menyatakan bahwa petani dalam memilih jenis tanaman yang diusahakan tidak melalui perencanaan yang matang, melainkan tergantung ketersediaan bibit di wilayahnya sehingga tidak mampu memberikan kontribusi yang optimal bagi pendapatan petani. Berdasarkan uraian latar belakang di atas, maka penulis merasa perlu melakukan penelitian tentang "Karakteristik Fungsional Agroforestri dan Kontribusinya Terhadap Pendapatan Masyarakat", hasil penelitian ini diharapkan dapat bermanfaat 
bagi seluruh pihak yang berkepentingan dengan pengembangan hutan rakyat berbasis agroforestry.

\section{METODE PENELITIAN}

\subsection{Waktu dan Tempat}

Lokasi penelitian di dua desa yaitu Majannang dan Manimbahoi Kecamatan Parigi Kabupaten Gowa. Pemilihan lokasi penelitian dilakukan secara purposive (sengaja) yaitu pada kelompok tani yang berada di dua desa tersebut dengan mempertimbangkan keadaan topografi dan kondisi wilayahnya

\subsection{Teknik Pengambilan Data}

Pengumpulan data primer meliputi data kuantitatif dilakukan melalui survei yaitu mengambil sampel dari suatu populasi dan menggunakan kuesioner serta pengumpulan data kualitatif dilakukan dengan menggunakan metode wawancara mendalam terhadap informan maupun responden yang didasarkan pada panduan wawancara . Metode lain yang digunakan adalah melalui observasi lapang di lokasi penelitian guna melihat fenomena aktual yang terjadi Pengumpulan data sekunder diperoleh melalui kantor desa, kantor camat, instansi terkait dan literatur-litaratur yang relevan dengan penelitian ini meliputi keadaan demografi penduduk, seperti jumlah penduduk berdasarkan umur, jenis kelamin, tingkat pendidikan dan mata pencaharian

\subsection{Analisis Data}

Potensi tanaman semusim, merupakan nilai produksi yang dapat dihasilkan dari usaha tani per musim tanam yang dinilai dengan mata uang, dihitung dengan persamaan yang dikemukakan oleh (Soekartawi, 2002).

TR $=$ Y.Py

Dimana:

$\mathrm{TR}=$ Total penerimaan $(\mathrm{Rp})$

$\mathrm{Y}=$ Produksi $(\mathrm{kg})$

$P y=$ Harga $Y(R p)$

Dalam pengusahaan tanaman semusim biasanya ditemukan lebih dari satu komoditas yang dikembangkan sehingga total biaya dihitung dengan menggunakan persamaan : 
n

$\mathrm{TC}=\sum \mathrm{XiPxi}$

$i=1$

Dimana:

TC = Total Biaya

$\mathrm{Xi} \quad=$ Jumlah fisik dari input yang membentuk biaya

Pxi = Harga input

$\mathrm{n} \quad=$ Macam Input

Pendapatan usaha tani adalah selisih antara penerimaan dan semua biaya.

$P d=T R-T C$

Dimana :

Pd = Pendapatan usahatani $(R p)$

$T R \quad=$ Total Penerimaan $(R p)$

TC = Total Biaya $(R p)$

Kontribusi hasil pengelolaan agroforestri lahan kebun pekarangan terhadap penduduk desa setempat dapat diasumsikan dengan rumus :

$$
K=\frac{L u}{L u+\operatorname{In} u} x 100 \%
$$

Dimana :

$K=$ Kontribusi Usaha pengelolaan agroforestri

Lu = Pendapatan usaha pengelolaan agroforestri

Inu = Pendapatan diluar usaha pengelolaan agroforestry

\section{HASIL DAN PEMBAHASAN}

\subsection{Potensi Agroforestri di Desa Sapobonto}

Pendapatan total petani dihitung dalam jangka waktu satu tahun terakhir sesuai dengan yang diperoleh petani dari masing-masing pekerjaan baik dari agroforestri maupun dari luar agroforestri. 
Pendapatan agroforestri meliputi pendapatan yang diperoleh dari penjualan hasil kebun seperti cengkeh, merica dan lainnya. Pendapatan dari luar agroforestri meliputi penerimaan dari hasil bertani, jasa dan lainnya. Pendapatan total petani di desa Sapobonto dapat dilihat pada Tabel 1.

Tabel 1. Pendapatan Petani Agroforestri Di Desa Sapobonto

\begin{tabular}{lccc}
\hline Sumber Pendapatan & $\begin{array}{c}\text { Pedapatan } \\
\text { Total }\end{array}$ & $\begin{array}{c}\text { Rata-Rata } \\
\text { Pendapatan/Tahun }\end{array}$ & Presentase \\
& $\mathbf{( R p / T h )}$ & $\mathbf{( R p / T h )}$ & $\mathbf{( \% )}$ \\
\cline { 2 - 4 } Agroforestri & 34.655 .944 & 4.331 .993 & 9,25 \\
Kayu & 14.943 .000 & 1.867 .875 & 3,99 \\
Pertanian & 227.709 .000 & 28.463 .625 & 60,77 \\
Perkebunan & 18.650 .250 & 2.331 .281 & 4,98 \\
Buah-Buahan & & & \\
Non Agroforestri & 14.720 .000 & 7.360 .000 & 3,93 \\
Jasa & 28.000 .000 & 9.333 .333 & 7,47 \\
Petani & 36.000 .000 & 12.000 .000 & 9,61 \\
Pensiunan & 476.431 .650 & 65.688 .107 & 100 \\
Total & & & \\
\hline
\end{tabular}

Berdasarkan Tabel 1 bahwa pendapatan agroforestri terbagi menjadi tanaman pertanian, perkebunan dan buah-buahan. Tanaman perkebunan seperti cengkeh, merica dan pala memperoleh sebagian besar dari hasil pendapatan yaitu sebesar $60,77 \%$ dikarenakan tanaman tersebut termasuk tanaman yang telah dikembangkan dari sejak dulu serta memiliki nilai ekonomi yang tinggi sehingga petani mendapatkan pemasukan secara terus menerus untuk memenuhi kebutuhan hidup sehari-hari. Kemudian diikuti dengan jenis tanaman kayu sebesar 9,25\%, kemudian tanaman buah-buahan sebesar 4,98. Jenis buah-buahan yang mendominasi di Desa Sapobonto antara lain durian dan rambutan. Sebagian besar petani menanam durian dan rambutan sebagai pendapatan sampingan selain cengkeh dan pala sebagai tanaman utamanya. Selain itu petani juga mendapatkan pendapatan dari tanaman pertanian seperti cabai, jahe merah dan lainnya sebagai tanaman sampingan diantara tanaman utama yankni sebesar 3,99\%.

Pendapatan terbesar dari non agroforestri diperoleh dari pekerjaan sebagai pensiunan pegawai negeri yaitu sebesar $9,61 \%$. Pekerjaan sebagai petani sawah memberikan pendapatan sebesar 7,47\%, mayoritas petani yang ada menggarap sawah padah tanah miliknya sendiri. Sedangkan pendapatan dari hasil jasa (tukang ojek) sebesar 3,93\%. 


\subsection{Potensi agroforestri di Desa Balang Taroang}

Pendapatan total petani dihitung dalam jangka waktu satu tahun terakhir sesuai dengan yang diperoleh petani dari masing-masing pekerjaan baik dari agroforestri maupun dari luar agroforestri. Pendapatan agroforestri meliputi pendapatan yang diperoleh dari penjualan hasil kebun seperti cengkeh, merica dan lainnya. Pendapatan dari luar agroforestri meliputi penerimaan dari hasil bertani, jasa dan lainnya. Pendapatan petani di desa Balangtaroang dapat dilihat pada Tabel 2.

Tabel 2. Pendapatan Petani Agroforestri Di Desa Balang Taroang

\begin{tabular}{lrrl}
\hline Sumber Pendapatan & Pedapatan Total & $\begin{array}{c}\text { Rata-rata } \\
\text { Pendapatan/tahun }\end{array}$ & Presentase \\
& \multicolumn{1}{c}{$(\mathbf{R p} / \mathbf{T h})$} & $\mathbf{( R p / t h )}$ & $\mathbf{( \% )}$ \\
\cline { 2 - 4 } Agroforestri & 37.175 .150 & 4.646 .893 & 8 \\
kayu & 9.261 .500 & 1.157 .688 & 1,94 \\
Pertanian & 310.923 .250 & 38.865 .406 & 65,26 \\
Perkebunan & 19.671 .750 & 3.146 .469 & 4,13 \\
Buah-buahan & & & \\
Non Agroforestri & 25.000 .000 & 25.000 .000 & 5,25 \\
Pedagang & 18.400 .000 & 6.133 .333 & 3,86 \\
Jasa & 32.000 .000 & 16.000 .000 & 6,72 \\
Peternak & 24.000 .000 & 12.000 .000 & 5,04 \\
Pensiunan & 476.431 .650 & 106.949 .789 & 100 \\
Total & & & \\
\hline
\end{tabular}

Berdasarkan Table 2 bahwa pendapatan agroforestri terbagi menjadi tanaman pertanian, kehutanan, perkebunan dan buah-buahan. Tanaman perkebunan seperti cengkeh, merica dan pala memperoleh sebagian besar dari hasil pendapatan yaitu sebesar $65,26 \%$ dikarenakan tanaman tersebut termasuk tanaman yang telah dikembangkan dari sejak dulu serta memiliki nilai ekonomi yang tinggi sehingga petani mendapatkan pemasukan secara terus menerus untuk memenuhi kebutuhan hidup sehari-hari. Tanaman kehutanan sebesar $8 \%$. Kemudian diikuti dengan jenis tanaman buah-buahan sebesar 4,13\%. Jenis buah-buahan yang mendominasi di Desa Balang Taroang antara lain durian dan rambutan. Sebagian besar petani menanam durian dan rambutan sebagai pendapatan sampingan selain cengkeh dan pala sebagai tanaman utamanya. Selain itu petani juga mendapatkan pendapatan dari tanaman pertanian seperti cabai, jahe, talas dan lainnya sebagai tanaman sampingan diantara tanaman utama yankni sebesar $1,94 \%$. 
Pendapatan terbesar dari non agroforestri diperoleh dari pekerjaan sebagai pensiunan peternak yaitu sebesar $6,72 \%$. Lalu pekerjaan sebagai pedagang sebesar 5,25 . Pekerjaan sebagai pensiunan memberikan pendapatan sebesar 5,04\%, Sedangkan pendapatan dari hasil jasa sebagai buruh bangunan dan bengkel las sebesar 3,86\%. Dari hasil wawancara banyak petani yang melakukan pekerjaan lain sambil menunggu tanaman dikebun panen. Hal ini disebabkan kurangnya pemasukan petani untuk pemenuhan sehari-hari dan untuk mengisi waktu luang pada saat tidak ada pekerjaan di kebun sehingga petani mendapatkan keuntungan walaupun sedang tidak mengalami panen

\subsection{Potensi Agroforestri di Kelurahan Jawi-jawi}

Pendapatan total petani dihitung dalam jangka waktu satu tahun terakhir sesuai dengan yang diperoleh petani dari masing-masing pekerjaan baik dari agroforestri maupun dari luar agroforestri. Pendapatan agroforestri meliputi pendapatan yang diperoleh dari penjualan hasil kebun seperti cengkeh, merica dan lainnya. Pendapatan dari luar agroforestri meliputi penerimaan dari hasil bertani, jasa dan lainnya. Pendapatan petani di Kelurahan Jawi-jawi dapat dilihat pada Tabel 3.

Tabel 3. Pendapatan petani agroforestri di Kelurahan Jawi-jawi

\begin{tabular}{|c|c|c|c|}
\hline Sumber Pendapatan & $\begin{array}{c}\text { Pedapatan } \\
\text { Total }\end{array}$ & $\begin{array}{c}\text { Rata-rata } \\
\text { Pendapatan/tahun }\end{array}$ & Presentase \\
\hline & $(\mathbf{R p} / \mathrm{Th})$ & $(\mathrm{Rp} / \mathrm{th})$ & $(\%)$ \\
\hline \multicolumn{4}{|l|}{ Agroforestri } \\
\hline kayu & 40.675 .890 & 5.084 .486 & \\
\hline Pertanian & 21.793 .000 & 2.724 .125 & 4,44 \\
\hline Perkebunan & 289.673 .250 & 36.209 .156 & 58,96 \\
\hline Buah-buahan & 31.196 .750 & 3.899 .594 & 6,35 \\
\hline \multicolumn{4}{|l|}{ Non agroforestri } \\
\hline pedagang & 52.000 .000 & 13.000 .000 & 10,58 \\
\hline peternak & 26.000 .000 & 13.000 .000 & 5,29 \\
\hline pensiunan & 30.000 .000 & 15.000 .000 & 6,11 \\
\hline total & 491.338 .890 & 88.917 .361 & 100 \\
\hline
\end{tabular}

Berdasarkan Tabel 3 bahwa pendapatan agroforestri terbagi menjadi tanaman pertanian, kehutanan, perkebunan dan buah-buahan. Tanaman perkebunan seperti cengkeh,vanili, karet dan pala memperoleh sebagian besar dari hasil pendapatan yaitu sebesar 58,96\% dikarenakan tanaman tersebut termasuk tanaman yang telah dikembangkan dari sejak dulu serta memiliki nilai 
ekonomi yang tinggi sehingga petani mendapatkan pemasukan secara terus menerus untuk memenuhi kebutuhan hidup sehari-hari. Lalu diikuti oleh tanaman berkayu seperti sengon dan bitti sebesar $8 \%$. Kemudian diikuti dengan jenis tanaman buah-buahan sebesar 6,35\%. Jenis buahbuahan yang mendominasi di kelurahan Jawi-jawi antara lain durian, langsat dan rambutan. Sebagian besar petani menanam durian dan rambutan sebagai pendapatan sampingan selain cengkeh dan pala sebagai tanaman utamanya. Selain itu petani juga mendapatkan pendapatan dari tanaman pertanian seperti cabai, jahe, talas dan lainnya sebagai tanaman sampingan diantara tanaman utama yankni sebesar $4,44 \%$.

Pendapatan terbesar dari non agroforestri diperoleh dari pekerjaan sebagai pedagang yaitu sebesar 10,58\%. Lalu pendapatan dari gaji pensiun sebesar $6,11 \%$. Pekerjaan sebagai peternak memberikan pendapatan sebesar $5,29 \%$. Dari hasil wawancara banyak petani yang melakukan pekerjaan lain sambil menunggu tanaman di kebun panen. Hal ini disebabkan kurangnya pemasukan petani untuk pemenuhan sehari-hari dan untuk mengisi waktu luang pada saat tidak ada pekerjaan di kebun sehingga petani mendapatkan keuntungan walaupun sedang tidak mengalami panen.

\subsection{Kontribusi Agroforestri Terhadap Pendapatan Total Masyarakat}

Kontribusi yang dimaksud dalam penelitian ini adalah sumbangan dari usaha kebun campur yang dilakukan di daerah penelitian sebanyak 24 responden. Usahatani agroforestri di Kecamatan Bulukumpa diusahakan oleh para petani untuk memperoleh pendapatan demi memenuhi kebutuhan sehari harinya. Pada umumnya, kontribusi yang diperoleh dari hasil agroforestri sangat membantu dalam pemenuhan kebutuhan sehari-hari. Jika besar kontribusi yang diberikan agroforestri sebesar $10 \%$ dari total pendapatan sudah sangat membant $u$ dalam pemenuhan kebutuhan (Suharjito, 2000 dalam Octavianingsih, 2010). Selain dari agroforestri masyarakat di kecamatan Bulukumpa juga memperoleh pendapatan dari kegiatan lain. Pendapatan rumah tangga dari padi, berdagang, berternak atau lain sebagainnya baik yang dikerjakan kepala keluarga maupun anggota keluarga. Besaran kontribusi yang dihasilakan dari kegiatan agroforestry terhadap pendapatan masyarakat dapat dilihat pada Tabel 4.

Tabel 4. Kontribusi agroforestri terhadap Pendapatan Masyarakat

\begin{tabular}{lrr}
\hline $\begin{array}{c}\text { Sumber } \\
\text { Pendapatan }\end{array}$ & $\begin{array}{c}\text { Jumlah } \\
\text { Pendapatan }\end{array}$ & Presentase \\
\hline Agroforestri & 1.056 .328 .73 & 78,69 \\
Non Agroforestri & 286.120 .00 & 21,31 \\
Jumlah & 1.342 .448 .73 & 100 \\
\hline
\end{tabular}


Berdasarkan tabel 4 dapat disimpulkan bahwa kontribusi agroforestri terhadap pendapatan total rumah tangga adalah sebesar $78.69 \%$. Hal ini menunjukkan lebih dari separuh Pendapatan rumah tangga masyarakat berasal dari agroforestri. Pengembangan agroforestri memberikan kontribusi cukup besar terhadap Pendapatan total rumah tangga masyarakat, dan pendapatan tersebut digunakan petani untuk memenuhi kebutuhan keluarga, seperti biaya makan sehari-hari, biaya sekolah anak dan lain sebagainya. Dilain sisi kontribusi dari non agroforestri sebesar $21,31 \%$, hal ini menunjukkan jika masyarakat sangat bergantung pada kebun agroforestrinya sedangkan untuk pendapatan diluar agroforestrinya hanya sebagai sampingan dalam menambah pendapatannya.

\section{KESIMPULAN}

Potensi pengelolaan lahan perkebunan menjadi lahan agroforestry bagi masyarakat khususnya di Kecamatan Bulukumpa mampu memberikan kontribusi yang besar terhadap pendapatan total masyarakat yakni sebesar $78,69 \%$. Dengan melihat besarnya kontribusi yang dihasilkan melalui kegiatan agroforestry, sehingga dengan menggunakan tekhnik-tekhnik agroforestry yang tepat masyarakat mampu mengadopsi tekhnik ini sebagai sebuah sistem yang tepat dalam mengelola lahannya di kemudian hari.

\section{DAFTAR PUSTAKA}

Irwanto. 2007. Analisis Vegetasi untuk Pengelolaan Kawasan Hutan Lindung Pulau Marsegu, Kabupaten Seram Barat, Provinsi Maluku. Sekolah Pasca Sarjana, Universitas Gadjah Mada. Yogyakarta.

Nurrochmat. 2005. Strategi Pengelolaan Hutan. Pustaka Pelajar. Yogyakarta.

Octavianingsih, Dian. 2010. Kontribusi Hutan Rakyat Terhadap Kesejahteraan Rumah Tangga Petani Hutan Rakyat (Studi kasus di Kecamatan Ngilpar, Semin dan Paliyan, Kabupaten Gunungkidul, Yogyakarta tahun 2009). Skripsi Fakultas Kehutanan. Institut Pertanian Bogor.

Sanchez, P.A. 1995. Science in agroforestry. Agroforestry system 30 ; 5-55 Soekartawi, 1995, Analisis Usaha Tani, UI-Press, Jakarta

Widiarti, A. \& Sukaesih, P. 2008. Karakteristik Hutan Rakyat Pola Kebun Campuran. Bogor. 